Publication Source:

Scott, B.D. Argumentation and the Challenge of Time: Perelman, Temporality, and the Future of Argument. Argumentation 34, 25-37 (2020). https://doi.org/10.1007/s10503-019-09493-Z

\title{
Argumentation and the Challenge of Time: Perelman, Temporality, and the Future of Argument
}

\author{
Blake D. Scott \\ Institute of Philosophy, KU Leuven \\ Kardinaal Mercierplein 2, 3000 Leuven, Belgium \\ blake.scott@kuleuven.be \\ https://orcid.org/0000-0002-0727-3330
}

\begin{abstract}
Central to Perelman and Olbrechts-Tyteca's philosophical revival of rhetoric and dialectic is the importance given to the temporal character of argumentation. Unlike demonstration, situated within the "empty time" of a single instant, the authors of The New Rhetoric understand argumentation as an action that unfolds within the "full time" of meaningful human life. By taking a broader view of his work beyond The New Rhetoric, I first outline Perelman's understanding of time and temporality and the challenge that it poses for the study of argumentation. Next, I emphasize the distinction between argumentation's internal and external temporal structures, and then show how Perelman problematizes a static view of a number of basic argumentative concepts by bringing out their essentially temporal character. Finally, in clarifying what is at stake in Perelman's account, I conclude by drawing attention to a number of issues in contemporary argumentation studies that may benefit from a reconsideration of Perelman's analysis of time.
\end{abstract}

Keywords New Rhetoric; Olbrechts-Tyteca; Perelman; Philosophy, Rhetoric; Temporality 


\section{Introduction}

Inaugurating what would prove to be one of the century's most prominent philosophical problems, in his 1905 lectures on time, Edmund Husserl laments that modern thought has failed to surpass, or even match, the great achievements of Augustine in grappling with the problem of time (Husserl 1991, p. 3). What makes thinking about time so difficult for Augustine is its apparent simplicity. For although we seem to know what is meant when we speak about time, "Who can explain this easily and briefly?", he asks; "Who can comprehend this even in thought so as to articulate the answer in words?" (Augustine 1991, p. 230) It is in view of responding to such questions that the likes of Bergson, Husserl, and Heidegger, among many others, had attempted to rethink longstanding philosophical problems in terms of a temporal problematic. While this convergence of philosophical interest on time and temporality can be seen as a common theme in $20^{\text {th }}$ century thought, what was perhaps less common was the attempt to connect these philosophical developments, and the theoretical and practical challenges that they raise, to more specific areas of study. Fortunately, however, this was not the case for the study of argumentation.

Appearing in 1958 alongside The New Rhetoric, Chaïm Perelman and Lucie OlbrechtsTyteca published a number of companion articles further developing some of the ideas that had been treated in the larger volume. It is only here, primarily in an essay devoted to temporality, that we learn the extent to which they had considered the problem of time to be central to the study of argumentation. As it is not immediately evident that Perelman and Olbrechts-Tyteca are interested in philosophical problems of temporality from reading The New Rhetoric on its own, what I want to convey to argumentation theorists who might be less familiar with the whole of their work is a sense of just what is at stake in taking the temporal characteristics of argumentation seriously.

When approached from a temporal point of view, or so I will argue here, Perelman and Olbrechts-Tyteca's philosophical contribution to argumentation theory can be seen as more than a historical footnote. On this reading, their efforts can be seen to initiate a philosophical rethinking of the nature of argumentation that stands as a live challenge to be met by contemporary argumentation research, which continues to operate with a largely static understanding of reason foreign to argumentation's dynamic nature. In short, the challenge posed to us today by Perelman and Olbrechts-Tyteca's essentially temporal understanding of argumentation is this: given its temporal nature, how can we theorize argumentation without distorting the set of practices that we want to (descriptively) understand and (prescriptively) improve?

After clarifying the way in which I interpret the philosophical intentions of the New Rhetoric project, in what follows I will outline Perelman's understanding of time and temporality as it relates to the study of argumentation. This will involve taking a broader view of Perelman's work beyond The New Rhetoric. Of particular interest here will be Perelman and OlbrechtsTyteca's 1958 essay, "On Temporality as a Characteristic of Argumentation". ${ }^{1}$ Here, a distinction is made between internal and external temporality that helps to clarify the many ways in which argumentation is said to be temporal. From the vantage point offered by this essay, I will then show how Perelman problematizes a static view of a number of basic argumentative concepts by

\footnotetext{
${ }^{1}$ To avoid confusing Perelman and Olbrechts-Tyteca's essay with the commentary provided by Bolduc and Frank accompanying their English translation, when referring to the former I cite the pagination of the original French version from Perelman's Rhétoriques (2012a). When citing Perelman and Olbrechts-Tyteca I also include the corresponding pagination from Bolduc and Frank's English translation in brackets for comparison. Unless indicated otherwise the translations used are those of Bolduc and Frank.
} 
bringing out their essentially temporal character. Finally, I will conclude by drawing attention to a number of issues in contemporary argumentation studies that may benefit from a reconsideration of Perelman's analysis of time.

\section{The Challenge of Time}

I would like to begin by addressing the question of how I will be interpreting The New Rhetoric in light of Perelman's other works and collaborations with Olbrechts-Tyteca. The reason for this is that The New Rhetoric, as a standalone text, is perhaps less clear in its presentation than it could have been. Michelle K. Bolduc and David A. Frank, for example, hypothesize that this may be due to space limitations imposed by the publisher (Bolduc \& Frank 2012, p. 309). Whatever the cause, it remains necessary to justify not only how one approaches The New Rhetoric, but also how one understands it in relation to the larger body of work of which it is only a fragment. For this reason, before discussing Perelman's conception of temporality directly, I first want to make clear how I will be approaching the New Rhetoric project as a whole.

Exemplary of the interpretive difficulties surrounding The New Rhetoric is the issue of its stance toward truth. According to some critics, given its central preoccupation with audiences Perelman's framework for understanding argumentation cannot help but reduce the validity of argumentation to its effectiveness. ${ }^{2}$ Although this reading is plausible from a certain philosophical perspective, it neglects an important methodological consideration raised, among other places, in the introduction to The New Rhetoric. Anticipating this criticism, Perelman and Olbrechts-Tyteca are clear that it is not their intention to study argumentation as a branch of experimental psychology — in which arguments would be tested on various audiences in order to determine their empirical effectiveness. On the contrary, what they propose is, "first of all, to characterize the different argumentative structures, the analysis of which must precede all experimental tests of...effectiveness" (Perelman \& Olbrechts-Tyteca 1969, p. 9, my emphasis). While there may of course be a discrepancy between these intentions and their actual execution, in order to be faithful to the aims of the project it is important that we study these different "argumentative structures" in the way that they were intended - as philosophical concepts that precede empirical analysis. In this case, taking our distinguished authors seriously means suspending certain epistemological assumptions that would prevent us from following their lead for fear that it might needlessly burden, or even render impossible, the task of evaluation down the road. In light of these methodological intentions, I will thus be approaching temporality, perhaps the central argumentative structure for Perelman and Olbrechts-Tyteca, primarily as a philosophical problem concerning the nature of argumentation itself.

How then does Perelman understand temporality in argumentation, and why is it so central to its study? In their 1958 companion essay to The New Rhetoric, Perelman and Olbrechts-Tyteca make clear that the justification for their primary distinction between demonstration and argumentation rests upon a temporal difference. It is "precisely the intervention of time", they write, "that best allows us to distinguish argumentation from demonstration" (Perelman 2012a, p. 373 (316)). The "essential difference" being that while "time plays no role in demonstration", it is "primordial in argumentation" (Ibid., p. 373 (316), translation modified). Unlike demonstration, which they contend is situated within the "empty time" of an eternal present, the authors of The New Rhetoric understand argumentation as form of action that unfolds within the "full time" of

\footnotetext{
${ }^{2}$ For an overview of critical appraisals of the New Rhetoric, see van Eemeran et al. (2014), 289-293.
} 
meaningful human life (Ibid., p. 374 (316), 388 (325)). What is at issue in this distinction is thus not only an attempt at clarifying the difference between two often confused notions, but more fundamentally a question of our basic philosophical orientation toward the primordial temporality of argumentation and how this temporality is reflected in our theoretical accounts.

As it is not my aim here to defend the distinction between argumentation and demonstration from criticism, I raise it only to highlight Perelman and Olbrechts-Tyteca's positive characterization of argumentation as being essentially temporal. Against a static way of conceiving argumentation, Perelman's temporal understanding invites us today to reconsider whether our own theoretical framework of conceiving argumentation is temporally adequate to its object. By analogy, we could say that a temporally inadequate understanding of argumentation would be something like trying to understand a film from a series of isolated snapshots. Although static, synchronic images of important scenes may in some cases be helpful to film students and critics, or even the casual viewer who thinks they may have spotted a poorly placed microphone in the last wide shot, these slices of time remain ill-suited to serve as representations of the film's essential diachrony. When it comes to argumentation, the challenge that this diachrony presents is twofold: (1) whether the theory that we bring to bear in interpreting and analyzing arguments leaves us with something that is faithful to the original phenomenon, i.e. the "total argumentative situation"; and (2) whether the application of a theory imposes an overly simplified representation of argumentation back into the "full time" of meaningful human life.

Although I do not claim to resolve these questions here, what I hope to contribute is simply an exploration and clarification of the ways in which Perelman and Olbrechts-Tyteca understand argumentation in a temporal way. Such a clarification is necessary because argumentation scholars, given their various disciplinary backgrounds, do not always share the same conception of argumentation, let alone a similar understanding of rationality. By exploring the way that Perelman and Olbrechts-Tyteca understand the rationality of argumentation in terms of its temporal articulations, it should be possible for scholars to reassess the original phenomenon we are investigating and find ways of converging our efforts around it. My wager here is that rather than needlessly complicating argumentation, a temporal reassessment may in fact prevent us from oversimplifying it.

\section{The Temporal Structures of Argumentation}

If it is "the intervention of time that best allows us to distinguish argumentation from demonstration", the first question to ask of Perelman and Olbrechts-Tyteca is what exactly they mean by "intervention" (Ibid., p. 373 (316). I propose that they understand time to intervene in argumentation in two ways, which I will unpack in terms of a distinction between internal and external structures of temporality. Such a distinction, which to my knowledge has not been made by either commentators of Perelman and Olbrechts-Tyteca or argumentation theorists, should help us reorient our theoretical lens around argumentation's own practical articulations. For reasons of time and space I will focus primarily on the latter.

\section{The external temporality of argumentation}

By "external structures" I understand Perelman and Olbrechts-Tyteca to mean the set of essential factors in any argumentative situation that pre-exist the actual argumentation. In general, 
these external factors function as constraints upon those engaged in an argumentative situation and can be considered as aspects of what is often called "context". Typically, however, these external factors are understood in spatial rather than temporal terms. Yet, even in saying that argumentation takes place, that is occurs or unfolds, we make implicit reference to a specific location and a specific time. These spatial and temporal references can be detected by a variety of means, the most obvious of which are linguistic and corporeal cues.

Beyond merely referencing time, however, Perelman and Olbrechts-Tyteca have in mind the temporal aspects of these external structures themselves. This includes elements such as the historical, cultural, and institutional constraints which give a determinate form and rhythm to the landscape of any argumentative situation. These external structures temporally constrain the choices of arguers and audiences. For example, concerning the choice of how much one should say at a given time, Perelman writes,

whatever the benefit of an accumulation of arguments, there are psychological, social, and economic limits that prevent a thoughtless amplification of discourse... This is the reason why each human group, each institution, has its rules and limits to be respected, which sometimes strictly regulate the time available for speaking. (Perelman 1982, p. 139)

Another obvious example along the same lines here would be-if Bolduc and Frank are rightThe New Rhetoric itself, which they report was originally over 2000 pages before the intervention of the publishers (Bolduc \& Frank 2012, p. 309). Similarly, in a court room we can also see that there are specific rules that stipulate when and for how long certain kinds of discourse are permissible. More spontaneous instances of argumentation, like those that take place over social media, are clearly constrained in different ways than those that take place in a court room; yet remain constrained in their own way nonetheless. In all of these cases, what is clear is that the external temporal structures of argumentation remain in place and establish the conditions in which arguers and audiences make their choices.

Although a good deal more could be said about the external temporality of argumentation, it is the internal structures of time that Perelman and Olbrechts-Tyteca are less clear on and which therefore merit more of our attention. Moreover, as almost all non-formal approaches to the study of argumentation would agree that temporality is relevant in the external sense, it is this second sense that I would like to emphasize, as its significance has been underappreciated in argumentation scholarship.

\section{The internal temporality of argumentation}

Moving from the above sketch of the external constraints of time on argumentation, we can now look at what happens when these external temporal structures are taken up within argumentative situations. As Perelman and Olbrechts-Tyteca suggest, the reason we need to make the distinction between internal and external temporality is that time affects "not only the events that argumentation is meant to influence or that which argumentation must take into account", but also "the very intimacy of argumentation's structure" (Perelman 2012a, p. 380 (321), translation modified). To understand argumentation's internal temporal structure, we need to first take a closer look at what it means for argumentation to be an action. 
From an internal point of view, temporality is an essential characteristic of argumentation to the extent that the set of actions we associate with argumentation-speaking, listening, analyzing, evaluating, etc.-all unfold temporally. ${ }^{3}$ To see how Perelman understands this "unfolding" we can begin by situating his understanding of argumentation against the background of his reinterpretation of Aristotle.

Like Perelman, Aristotle had also recognized the temporal aspects of rhetorical speech. As Aristotle writes in Book 1 of On Rhetoric, each of the three species or genres of rhetoric,

has its own "time"; for the deliberative speaker, the future (for whether exhorting or dissuading he advises about future events); for the speaker in court, the past (for he always prosecutes or defends concerning what has been done); in epideictic the present is the most important; for all speakers praise and blame in regard to existing qualities, but they often also make use of other things, both reminding [the audience] of the past and projecting the course of the future. (Aristotle, 2007, 1358a, p. 48-49)

Despite this emphasis on the time proper to each rhetorical genre, Perelman breaks away from Aristotle by reinterpreting the centrality of epideictic speech. Unlike Aristotle, Perelman understands epideictic speech as the root of rhetorical practice rather than one of its branches. For Perelman, this is because the global telos of any action, irrespective of its local aim and consequence, is to intensify the "consensus around certain values which one wants to see prevail and which should orient action in the future" (Perelman 1982, p. 20). It is thus because all actions have as their aim the intensification of particular values that Perelman understands all of practical philosophy to arise from the epideictic genre of rhetoric (Ibid., p. 20) By reinterpreting argumentative action in this epideictic way, Perelman is effectively redefining argumentation by including its aim or purpose within it. ${ }^{5}$ Because argumentation is telic in this way, it is possible to view arguments as having both temporal extension and enough discreteness to warrant talking about them as separate acts.

In The Realm of Rhetoric Perelman will define the specific aim of argumentation as follows: "the aim of argumentation...is to elicit or increase the adherence of the audience to theses presented for their assent" (Perelman 2012b, p. 28, my translation). By pausing to take a closer look at the concept of adherence in this definition, I now want to show how Perelman brings out its temporal character and how this example can allow us to view some of his other basic concepts in a similar way.

While the centrality of adherence in Perelman's writings is well known, it is only in "On Temporality as Characteristic of Argumentation" that its temporal character is explicitly thematized. What we learn about adherence in this text is the idea that a person's adherence always "goes beyond the present moment" (Perelman 2012a, p. 376 (318)). What I take Perelman to mean by this is that the concept of adherence is essentially temporal-in the same way that something like a promise cannot be understood without a temporal reference to a possible future where it is either honoured or broken. With respect to adherence, this is to say that what a person is intellectually and affectively committed to at a given point in time cannot be reduced to any

\footnotetext{
${ }^{3}$ This is also why Perelman wants to dissociate "adherence" from all ideas of "proof" found in rationalist theories of demonstration. These approaches rely upon a notion of immediate and intuitive "evidence" to account for the way in which the mind grasps propositions as being certain and true all in one go. See for example, "Évidence et preuve" and "Une théorie philosophique de l'argumentation" in Rhétoriques (2012a).

${ }^{4}$ All punctuation marks are Kennedy's.

${ }^{5}$ Tindale argues for something similar in The Philosophy of Argument and Audience Reception (2015), p. 23.
} 
particular "present". To put it another way, adherence cannot be understood independently of its past and future. On the side of the past, what we presently adhere to can be understood as a kind of personal precedent, as the past weighing on the present as a constraint on what we will consider to be argumentatively reasonable (from myself and from others). On the side of the future, we will find that adherence makes reference to a number of possible futures where, under certain conditions, we would be committed to acting in certain ways given our current configuration of value commitments.

As Perelman's conception of adherence involves our attachment to particular values, it should come as no surprise that these values too will be understood in a temporal way. As Perelman and Olbrechts-Tyteca explain in The New Rhetoric, the realm of values is a site of "intense activity" that is constantly being "recast and remodeled" (Perelman \& Olbrechts-Tyteca 1969, p. 79). Here they account for these changes at two different levels. First there is the level of the particular values to which one adheres with some degree of intensity. The second level is that of the specific configuration or hierarchy among particular values to which one also adheres with some degree of intensity. Apart from the quantitative and qualitive changes in our adherence to values, Perelman and Olbrechts-Tyteca are more interested here in accounting for the way in which these changes occur at a structural level. As we will see, the difference between these two levels is an important and recurring temporal structure in Perelman and Olbrechts-Tyteca's analyses.

I would argue that the difference between these two levels can be understood in terms of the distinction between the form and content of any process of argumentation. As they claim in The New Rhetoric, Perelman and Olbrechts-Tyteca "refuse to separate the form of a discourse from its content" (Perelman \& Olbrechts-Tyteca 2008, p. 192, my translation). Although they are also careful not to conflate the two, it is through the refusal to make this complete separation that they can distinguish between demonstration and argumentation in the first place. Where the demonstrative reasoning characteristic of formal logics can make a clear separation between a logical language and its metalanguage, those who are observing or are engaged in argumentation will find this distinction much more difficult to sustain. Yet, if Perelman and Olbrechts-Tyteca are correct, this is not due simply to human irrationality or laziness; there is a structural reason for this owing to argumentation's internal temporal structure.

As Perelman and Olbrechts-Tyteca observe, in argumentation "not only does the existence of spontaneous arguments cause reflection on the discourse to mix with the object of the discourse, but this object itself is situated on levels that vary constantly" (Perelman 2012a, p. 381 (322), translation modified). What they are trying to get at here is the idea that, unlike demonstration, argumentation cannot step away from its own shadow: even when argumentation shifts its attention from the object of discourse to the discourse itself, the effects of this shift remain internal to argumentation (Perelman 2012a, p. 382 (322)). What this means is that argumentation never has recourse to pre-given concepts and rules whose meanings and scope of application would fall outside of the motivating disagreement; argumentation presupposes that there is full agreement about neither content nor form. Thus, where such first-order disagreements in formal logics can in principle be resolved by stepping back to the second-order metalanguage, such disagreements in argumentation all happen within the same order-even if analytically we can distinguish between these two "levels".

The important temporal difference from demonstration here is that when it comes to arguing the shift between these two levels does not involve stepping outside of argumentation but rather involves moving forward in time along the same surface. Temporally speaking, 
argumentation can thus be understood as proceeding along the surface of a Möbius strip (Fig. 1), where form and content remain distinct without losing their fundamental unity.

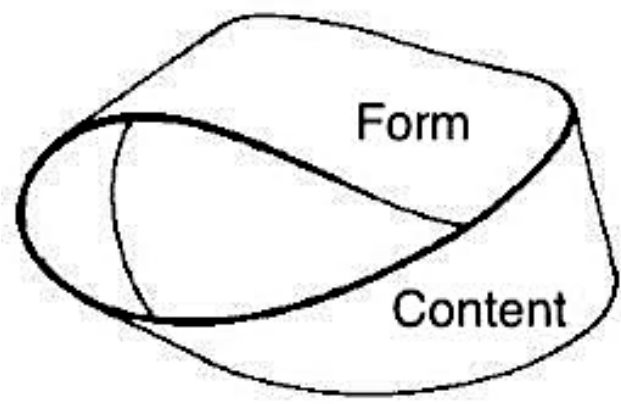

Fig. 1 The temporal unity of different argumentative levels

It is thus only through the unfolding of time within an argumentative situation that interlocutors can switch between levels and back again. It is because these points of reference cannot be fixed in advance, or for all time that Perelman and Olbrechts-Tyteca claim that this "game of possible levels", without any internal limit, can be played indefinitely (Perelman 2012a, p. 382 (323)). And it is because the internal temporality of argumentation is unlimited in this way that it is socially necessary for there to be external temporal limits on argumentation as we have already seen above.

By bringing together these various elements found among Perelman and OlbrechtsTyteca's writings, I have tried to (1) clarify the difference between the internal and external temporal structures of argumentation; and (2) emphasize the importance of argumentation's internal temporal structure, which can be seen as the motor of argumentation's internal movement. Moreover, I also have begun to show that there is more going on temporally in Perelman and Olbrechts-Tyteca's understanding of argumentation than can be gleaned from The New Rhetoric alone, which - unlike for philosophers and rhetoricians more familiar with their work - often remains the sole point of reference for argumentation theorists. To further illustrate this, I now want to briefly touch on a few other Perelmanian concepts that should be understood in a similarly temporal way to the extent that they also rely upon this same internal temporal structure.

\section{The rule of justice and the durability of the reasonable}

To reinforce the idea that the temporality of argumentation is not only a peripheral concern or of historical interest, let us take a look at one of Perelman's most central concepts, the "rule of justice". Perhaps here more than anywhere else, we can see the importance of temporality in describing how it is possible that we make normative assessments of arguments. Recalling that the maxim of the rule of justice is to "treat essentially similar cases similarly", we can immediately notice a parallel to our earlier treatment of the concept of adherence. Like adherence, the rule of justice involves an implicit temporal reference. In this case it involves, on the one hand, making a retrospective interpretation of relevance regarding what is "essentially similar" between the past and the present. On the other hand, in coming to make this judgment of relevance, we must also make reference to the future, which comes to constrain the way that we can interpret the past. As the example of a legal judgment makes clear, this is because our present judgment will come to serve as a precedent for future judgments. In a word, the rule of justice involves subsuming the 
present under the past with a cautious eye toward the future. The rule of justice is thus fundamentally Perelman's way of accounting for how it is possible that the past comes to weigh upon the present in a normative, or non-arbitrary way.

Digging deeper, Perelman accounts for the "weight" of this rule by means of another essentially temporal idea, what he calls the "principle of inertia". For Perelman, inertia functions more broadly as a stabilizing factor in argumentation; it is what allows us to explain our "application of the rule of justice to things that succeed one another in time" and how it is possible that we are able to treat "new situations and those that we have already encountered in the same manner" (Perelman 2012a, p. 387 (326-327), translation modified). It is thus through this inertia, he continues, that previously used arguments constitute "types of precedents whose value has been recognized because of their success... [and that] have become models, or schemes, that we can consider reliable" (Ibid., p. 387 (327), translation modified). ${ }^{6}$ The principle of inertia thus accounts for the temporal durability of these models or schemes, and how it is that we can rely upon them when forming judgments about the strengths and weaknesses of new arguments we encounter. As Perelman puts it, it is in this way that customs are born and "give a normative value to a habitual course of action" (Perelman 1982, p. 66).

What Perelman is here describing in temporal terms is the social constitution of what a community holds to be reasonable. At its most basic, the reasonable for Perelman can be understood as the space of possibility within an argumentative situation that constrains the choices that arguers and audiences can make outside of which they would likely violate the (often implicit) normative expectations of their audience. Even in less regulated instances of argumentation than, say, a court room, the constraining force of this reasonable precedent remains; it remains reasonable for interlocutors to hold each other to the same standards that have been applied to them. Perhaps unlike a legal trial, however, whether or not such a violation of precedent has occurred will have to be resolved within the argumentation itself, as we have already discussed above.

Without recourse to a judge in most situations, argumentation would then seem to be lost in its own Heraclitean stream. Does this mean that the problem of time is insurmountable outside of the courthouse and other such institutions? Does this mean that the evanescent nature of argumentation leaves us with nothing solid to grab hold of? To see Perelman's negative response to such questions will involve introducing into our discussion one final concept central to his work.

Beyond the stability offered by the principle of inertia, Perelman's second point of stability is that of "the person". For Perelman, it is ultimately the person that serves as the point of (relative) stability in the "succession of knots" that he calls argumentation. (Perelman 2012a, p. 388-389 (327-328)). It is because argumentation is invented by and for persons that it is even argumentation at all; as it is only with personal validity that rhetoric is concerned (Perelman 1982, p. 162). Thus, without access to a judge, a God, or absolute reason to guarantee argumentation from above, responsibility can only fall to the persons who, in risking their commitments by arguing, prevent argumentation from slipping into an infinite skepticism (Frank et al. 2003, p. 199).

\footnotetext{
${ }^{6}$ I have chosen "schemes" to translate "patrons", rather than "examples" as Bolduc and Frank do, because Perelman and Olbrechts-Tyteca's use of the term here is much closer to the contemporary meaning of "argumentation schemes" as found in Walton, Reed, and Macagno (2008), for example.
} 


\section{The Future of Time in Argumentation}

Before concluding, I would like to briefly point to some of the ways that contemporary argumentation studies may benefit from a reconsideration of temporality. One obvious theme that might benefit from a return to some of Perelman's ideas is the relationship between argumentation and narrativity. In recent years there has been a considerable amount of interest generated around this relationship (Olmos 2017; Danblon et al. 2008). Similar to what I have been discussing here, reflecting on the role of narrative and narrativity involves asking questions about the relationship between temporally extended units of meaning and the characters (or persons) implicated in them. Perhaps the reason for this is that, to quote Paul Ricoeur, "time becomes human to the extent that it is articulated through a narrative mode" (Ricoeur 1984, p. 52). On a similar note, Perelman's understanding of temporality would seem to suggest that beyond only using narratives as arguments, as some authors have discussed, at a more general level narrativity is fundamental to argumentation to the extent that arguments aim at a reconfiguration of the narratives already operative in any particular self-understanding.

Following the thread of Perelman's idea of the person, those interested in the idea of virtue argumentation may also stand to gain from thematizing the essentially temporal idea of ethos. ${ }^{7}$ As virtue argumentation is concerned with the virtues and vices of character that grant a certain stability to arguers and audiences, it would be interesting to know in more detail how it is that these habits sediment over time through argumentative practice - as well as how they might be undermined. Such analyses could also help to supplement Perelman's account of the person, which remains rather underdeveloped.

Along the same lines, scholars working on multimodal argumentation may also benefit from temporal considerations. ${ }^{8}$ For example, what makes something like visual argument so interesting from a Perelmanian point of view are the mereological differences among arguments transmitted through various media. Where an audience's attention is directed - and in what order - is central for Perelman in understanding how arguments are received. When looking at a poster, a television commercial, or a political meme on the internet, one's attention will be directed to the content in very different ways than the paradigmatic linear model appropriate to texts.

Finally, important questions have also been raised about the new forms of mediation that now house, direct, and incentivize our argumentative practices. What scholars interested in "argument design" point out, is the extent to which the contexts in which we argue are constructed and gradually refined over time (Jackson 2015) It is perhaps here more than anywhere else, at the level of what Mark Aakhus calls our "argumentative realities" (Aakhus 2017), that an essentially temporal understanding of argumentation is necessary. By shifting our theoretical focus from individual arguers and audiences to the dynamism of argument networks themselves, we can begin to study what goes on behind the backs of those engaged in argument "on the ground". Taking the study of argumentation in this direction, however, raises important questions about the agency of individuals within these networks, and to what extent conventional understandings of reason and rationality remain relevant in the digital age.

\footnotetext{
${ }^{7}$ See, for example, Aberdein, (2010); Gascón, "Virtue and Arguers" (2014);

${ }^{8}$ For an overview of some of the developments in visual argumentation, see Groarke et al, (2016).
} 


\section{Conclusion}

In this article I have brought together some of the various threads in Perelman and OlbrechtsTyteca's work that attest to the continued relevance of their understanding of temporality for contemporary argumentation research. In doing so I have tried to illustrate that their conception of argumentation is not only concerned with the external temporality of argumentation, but more importantly its internal temporality, which is what essentially characterizes argumentation and allows us to distinguish it from demonstration. Above all, argumentation is essentially temporal because the set of social practices that we call argumentation, as well as the meanings of the concepts that we use to make sense of them, all unfold through time. The unfolding of argumentation through time prevents it from being understood as a series of externally related "now" moments that could be analyzed frame by frame, as it were. Although such simplifications can sometimes be necessary, we should always be aware that the extraction of argumentative data from the "full time" of its original context will sever many of the internal temporal relations that give arguments their full meaning. Warning against this, Perelman and Olbrechts-Tyteca's work remains unmatched in its attempt to rethink basic philosophical concepts of argumentation in a way that is adequate to its temporal nature. As I have illustrated here, most interesting is their attempt to think the difference between the form and content of argumentation as a temporal unity. This allows us to distinguish between the various levels of argumentation in analysis without having to impose a static opposition not found in the original phenomenon.

Although such an understanding of argumentation makes its study markedly more difficult, at the same time as it closes off certain well-worn lines of thought it also opens up new ways of moving the study of argumentation forward. What the analysis of time and the other themes discussed above all illustrate is a general recognition of the need for an increasingly complex picture of argumentation. For what all of these developments have in common is the intention of further complicating the traditional image of argumentation as it has been inherited from a particular line of philosophical thought that could only defend an eternal conception of reason by suppressing the corrosive effects of time. Today, some may still worry that such temporal concerns born out of a rhetorical, rather than a logical analysis, ultimately remain peripheral to the hardnosed task of evaluating good and bad forms of reasoning. However, as Olbrechts-Tyteca reminds us, the virtue of a rhetorical perspective is that it provokes, "even on the level of pure logic, a permanent dissatisfaction that can only be stimulating" (Olbrechts-Tyteca 1963, p. 18, my translation). At the level of argumentation theory, she adds, it has the "merit of keeping us on guard against simplifications" (Ibid., my translation), which is worth bearing in mind for the future of the field.

\section{References}

Aakhus, Mark. 2017. The Communicative Work of Organizations in Shaping Argumentative Realities. Philosophy \& Technology 30: 191-208.

Aberdein, Andrew. 2010. Virtue in Argument. Argumentation 24: 165-179.

Augustine. 1991. Confessions, trans. Henry Chadwick. New York: Oxford University Press.

Aristotle. 2007. On Rhetoric: A Theory of Civic Discourse, $2^{\text {nd }}$ ed., trans. George A. Kennedy. New York: Oxford University Press. 
Bolduc, Michelle K. \& Frank, David A. 2012. Chaïm Perelman and Lucie Olbrechts-Tyteca's “On Temporality as a Characteristic of Argumentation". Philosophy \& Rhetoric 43(4): 308336.

Danblon, Emmanuelle, et al. (eds.). 2008. Argumentation et narration. Bruxelles : Éditions de l'Université de Bruxelles.

Frank, David A., et al. 2003. Chaïm Perelman's "First Philosophies and Regressive Philosophy": Commentary and Translation. Philosophy \& Rhetoric 36(3): 177-206.

Gasćon, José Ángel. 2016. Virtue and Arguers. Topoi 35: 441-450.

Groarke, Leo, et al. 2016. Navigating the Visual Turn in Argument. Argumentation and Advocacy 52(4): 217-235.

Husserl, Edmund. 1991. On the Phenomenology of the Consciousness of Internal Time (18931917), trans. John Barnett Brough. Dordrecht: Kluwer Academic Publishers.

Jackson, Sally. 2015. Design Thinking in Argumentation Theory and Practice. Argumentation 29: 243-263.

Olbrechts-Tyteca, Lucie. 1963. Rencontre avec la rhétorique. In La théorie de l'argumentation: Perspectives et applications, 3-18. Louvain: Éditions Nauwelaerts.

Olmos, Paula (ed.). 2017. Narration as Argument. Springer International Publishing.

Perelman, Chaïm. 1982. The Realm of Rhetoric, trans. William Kluback. Notre Dame: University of Notre Dame Press.

Perelman, Chaïm. 2012a. Rhétoriques, 2e. Bruxelles : Éditions de 1'Université de Bruxelles.

Perelman, Chaïm. 2012b. L'empire rhétorique: Rhétorique et argumentation, $2^{\mathrm{e}}$. Paris : VRIN.

Perelman, Chaïm \& Olbrechts-Tyteca, Lucie. 1969. The New Rhetoric: A Treatise on Argumentation, trans. John Wilkinson \& Purcell Weaver. Notre Dame: University of Notre Dame Press.

Perelman, Chaïm \& Olbrechts-Tyteca, Lucie. 2008. Traité de l'argumentation : La nouvelle rhétorique, $6^{\mathrm{e}}$. Bruxelles : Éditions de l'Université de Bruxelles.

Ricoeur, Paul. 1984. Time and Narrative, Volume 1, trans. Kathleen MacLaughlin \& David Pellauer. Chicago: The University of Chicago Press.

Tindale, Christopher W. 2015. The Philosophy of Argument and Audience Reception. Cambridge: Cambridge University Press.

van Eemeran, et al. 2014. Handbook of Argumentation Theory. Dordrecht: Springer.

Walton, D., Reed, C., \& Macagno, F. 2008. Argumentation Schemes. Cambridge: Cambridge University Press. 